\title{
Oyster Demand Adjustments to Counter-Information and Source Treatments in Response to Vibrio vulnificus
}

\author{
O. Ashton Morgan ${ }^{\mathrm{a}}$, Gregory S. Martin ${ }^{\mathrm{b}}$, and William L. Huth \\ ${ }^{a}$ Department of Economics \\ Appalachian State University \\ 3107 Raley Hall \\ 416 Howard Street \\ Boone, NC 28608 \\ ${ }^{\mathrm{b}}$ Department of Marketing \\ Sports Business Program \\ Northern Kentucky University \\ Highland Heights, KY 41099 \\ ${ }^{\mathrm{c}}$ Department of Marketing and Economics \\ University of West Florida \\ 11000 University Parkway \\ Pensacola, FL 32514
}

*This study was funded by the Florida Sea Grant Program (FSG [R/LR-E-19]).

**The authors would like to thank the anonymous reviewers of this journal for their useful comments and insight. 


\begin{abstract}
A web-based contingent behavior analysis is developed to quantity the effect of both negative and positive information treatments and post harvest processes (PHP) on demand for oysters. Results from a panel model indicate that consumers of raw and cooked oysters behave differently after news of an oyster-related human mortality. While cooked oyster consumers take precautionary measures against risk, raw oyster consumers exhibit optimistic bias and increase their consumption level. Further, by varying the source of a counter-information treatment, we find that source credibility impacts behavior. Oyster consumers, and in particular, raw oyster consumers, are most responsive to information provided by a not-for-profit, non-governmental organization. Finally, post harvest processing of oysters has no impact on demand.
\end{abstract}

Keywords: Oyster demand; consumer behavior; non-market valuation; Vibrio vulnificus; information treatments; source credibility; optimistic bias.

JEL Classifications: Q18, Q13, Q58. 


\section{Introduction}

Since Shulstad and Stoevener measured the welfare losses incurred by Oregon hunters in reaction to news of mercury contamination in pheasants, research in the food safety arena has examined the impact of information conveyance on consumer risk perceptions and behavior in the marketplace for a variety of products, including eggs, milk, seafood, and beef. ${ }^{1}$ One conclusion that can be drawn from the literature is that "health scare" information is subjectively evaluated by consumers and is critical to the risk perception formation process. In many instances, changes in risk perception can cause consumers to react defensively, reducing demand for the product and creating a loss in welfare even when there is no scientifically supported health risk from normal consumption (Swartz and Strand; Parsons et al.). ${ }^{2}$ In other cases, news of health hazards has no effect on consumer behavior (Miles and Frewer). In an attempt to explain the disparity in findings, researchers identified specific psychological factors that can influence consumer behavior and cause consumers to react differently to different hazards (Sparks and Shepherd; Shepherd; Miles and Scaife). One prominent factor is that, in some instances, individuals exhibit 'optimistic bias,' or an unrealistic expectation that they are less likely to experience negative events, such as food poisoning, than their peers. As such, they avoid any precautionary behavior following news of a health scare incident and do not change their behavior. This phenomenon has clear implications for information provision of natural hazards, as individuals may ignore risk messages, believing the information is directed at someone else.

Further still, Weinstein and Klein found that information conveying the risks of certain health hazards may even exaggerate optimistic bias, leading individuals to 
consume more of the good in question. Overall, the literature shows that consumer reaction to health hazards is idiosyncratic in nature and, as such, it is difficult to predict the impact of news of a specific hazard on consumer behavior. Our research adds weight to the debate on consumer behavior following a food hazard by examining oyster consumer behavior after news of a human mortality associated with oyster consumption.

We also examine the impact of a counter-information treatment on oyster consumer behavior following a health scare incident. Recent research has also attempted to quantify the impact of counter-information treatments, designed to reassure consumers about a product's safety, on consumer behavior (see Smith, van Ravenswaay, and Thompson; Brown and Schrader; Wessells and Anderson; Parsons et al.). In general, these studies find that different positive counter-information treatments have a negligible impact on consumer behavior and initial welfare losses, if they exist, persist. For example, Parsons et al. examined the welfare effects associated with news of fish kills linked to a harmful algae bloom known as Pfiesteria piscicida in Mid-Atlantic estuaries. Having estimated aggregate welfare losses of approximately $\$ 60$ million per month over a four-state region, Parsons et al. found that different counter-information treatments had no statistical impact on consumer behavior and welfare losses persisted.

While such research explicitly tests for the impact of different counterinformation treatments on consumer behavior, what is not examined is the role of the source, or the provider of information, in reassuring consumers about a product's safety after a health scare incident. In the psychology literature, source credibility has often been suggested as a potential cause of the asymmetrical impact of negative and positive information provision on consumer behavior (see Hovland and Weiss; Crano; Johnson 
and Steiner; Sternthal, Lynn, and Dholakia). Generally, this research suggests that more credible sources likely induce greater behavioral compliance, as does information that is perceived to be incongruous to the best interests of the source.

Within the agricultural economics literature, the only food safety research that considers the role of source credibility in information provision of which the authors are aware, is a study that uses a contingent valuation approach to measure consumers' willingness to pay for a seafood inspection program administered by different government agencies (Wessells and Anderson). They found that, on average, consumers were willing to pay an additional 31 cents per pound of seafood if the product was inspected by the National Marine Fisheries Service, 23 cents per pound if administered by the Food and Drug Administration, and 22 cents per pound for inspection by the U.S. Department of Agriculture. However, the focus of our research differs as we consider source credibility of both a government and not-for-profit organization. Also, we explicitly quantify the welfare mitigating effects of different treatment/source combinations on consumer behavior.

There is, however, a growing literature on the role of source information on demand for ecolabeling and genetically modified food labels, from which we can derive some useful insight. Generally, research in this field suggests that consumers are distrusting of information disseminated by government agencies, but demand can be influenced if consumers have access to independent, third party information (see Milgrom and Roberts; Johnston et al.; Huffman and Tegene; and Huffman et al.).

The objectives of this paper are three-fold. First, a contingent behavior analysis is developed to measure the welfare effects of a hypothetical news release regarding a 
human mortality from eating raw oysters contaminated with the pathogen Vibrio vulnificus (Vibrio v.). Under this scenario, we also test for response differences between consumers of raw and cooked oysters. Other research typically looks at all consumers of a product, even if they may not be directly linked to the specific contamination incident. For example, Parsons et al. examined the behavioral response of consumers of all seafood even though Pfiesteria only kills certain species of fish (such as menhaden and mullet). Likewise, Swartz and Strand considered the effects of contamination of the James River, Virginia, on demand for oysters in the Baltimore market, even though oysters harvested in the James River are not sold in Baltimore. Essentially, after news of the health scare, perceived risk of consuming the product can elevate even though the actual risk may be negligible or even zero. We follow this research by examining the effects of a health scare on all oyster consumers' (both raw and cooked) behavior. However, as Vibrio v. only affects consumers of raw oysters with specific health conditions, we also examine the marginal effects of news of an oyster-related health hazard on consumers of raw oysters.

Second, we examine behavioral responses after providing consumers with expert counter-information, reassuring individuals about oyster consumption safety. At this stage, the impact of the information provider (source) on oyster demand is evaluated by varying the source of the counter-information treatment across respondents. Identifying the effectiveness of an information treatment on consumer behavior, varied by source, may well provide important policy-based information as the oyster industry and state/federal agencies seek direction for future consumer educational outreach programs. 
Again, by differentiating between raw and cooked oyster consumers, we examine the marginal effects of our counter-information treatment on raw oyster consumers.

Finally, because previous research suggests that consumers tend to respond favorably to inspection programs that guarantee a product's quality, the impact of a generic post-harvest process (PHP) oyster treatment and related price premiums on consumer behavior is also examined. ${ }^{3}$

\section{Background - Vibrio vulnificus}

Vibrio v. is a gram-negative bacterium found naturally in warm, brackish, coastal waters, such as the Gulf of Mexico. It is found in higher concentrations in the summer months when coastal waters are warm and filter-feeding shellfish, including oysters, concentrate Vibrio v. in their tissues. Consumption of Vibrio v.-contaminated raw oysters by individuals with certain health conditions can cause life threatening illnesses, the most common of which is acute septicemia or blood poisoning. Those most at risk are individuals that suffer from various health conditions such as liver disease, iron overload disease, diabetes, cancer, or a weakened immune system. Risk of life threatening illness from consuming oysters arises primarily if the oysters are consumed raw or in an undercooked state. While healthy individuals have little life threatening infection risk from eating shellfish, those that are at risk can avoid infection by eating only shellfish that have been thoroughly cooked or processed to reduce Vibrio v. to non-detectable levels and by avoiding contact with seawater. In some instances Vibrio v.-related illness can lead to death; however, reported incidences of Vibrio v.-related illnesses are infrequent. To put it in perspective, an Interstate Shellfish Sanitation Conference (ISSC) 
educational brochure states that of the millions of oyster meals consumed each year in the U.S., the Food and Drug Administration (FDA) recorded only 341 Vibrio v.-related serious illnesses over a 14-year period from 1989 through 2002. Of the 341 cases, $98 \%$ were associated with consumption of raw oysters, of which 179 cases resulted in death. Corcoran also documents that each year more than 50 at-risk people become ill, of which, at least 10 individuals die from eating uncooked Gulf Coast oysters contaminated with Vibrio v. bacteria.

Oyster consumers' understanding of Vibrio v. risk and the impact on consumer marketplace behavior is a major concern for the oyster industry and relevant state and federal agencies. Heightened consumer perceptions of risk and misconceptions about how to reduce and manage the risk of Vibrio v. infection from oyster consumption are widespread. These perceptual issues and FDA mandates resulted in the development and implementation of educational and outreach programs to better inform consumers about the risks associated with Vibrio v. and research associated with these efforts has become a priority for state and federal regulatory agencies, as well as industry stakeholders. For example, the Florida Vibrio v. Risk Reduction Plan for Oysters states "The State of Florida believes that consumer education is the first and foremost tool to reduce illness related to Vibrio vulnificus" (Florida Department of Agriculture and Consumer Services, Division of Aquaculture).

\section{Survey and Study Design}

We developed a web-based contingent behavior analysis to measure the welfare effects associated with news of an oyster-related human mortality. We then measured the 
mitigating impacts of providing a consumer educational brochure (varied by source) and a PHP treatment and related price premium on individuals' demand for oyster meals.

The population of interest was defined as adults (aged 18 and over) who reside in a household in the state of Florida with a telephone and have access to the internet. Some consumer-focused oyster product studies have limited consumer samples to a small number of core production/consumption states (e.g., Flattery and Bashin, who sampled California, Florida, Louisiana, and Texas households), while others have sampled nationally (e.g., Hanson et al.). A Florida sample was used in order to focus on major markets for the Apalachicola, Florida oyster industry. A probability sample plan known in the marketing research industry as an "RDD sample" was used. In this sample plan, a commercial research list vendor generates a list of randomly selected telephone numbers to provide a representative sample of the state population.

Data collection was performed in two rounds. Round 1 was a telephone survey, administered at the time of initial telephone contact by the commercial market research firm. The round 1 survey instrument was designed to elicit pre-treatment baseline data for oyster consumption experience, attitudes, and preferences; reasons for consumption or non-consumption; awareness and perceptions of oyster consumption health risk; knowledge about oyster consumption health risk; and relevant demographic data. For use in estimation, we also asked respondents whether they consume raw or cooked oysters, or both. In addition, following Parsons et al., in order to calculate welfare estimates, respondents were also asked how their monthly oyster meals consumed would change if the price of an oyster meal were to rise. ${ }^{4}$ 
At the end of the telephone survey, respondents were asked if they would be willing to participate in the second round of the survey, administered through the project website. Two to three days after completion of their round 1 telephone interviews, respondents agreeing to participate in round 2 received an email containing instructions to follow a provided link to the project website for completion of the round 2 experiment. ${ }^{5}$ When entering the project web site, respondents were asked to confirm that they participated in the round 1 telephone study. Non-participants in round 1 were logged out with the message to please ask the actual respondent in their household to click into the site. Qualified respondents saw instructions for completing the survey and were asked if they had heard or seen additional information about oyster safety since their round 1 participation. The focus of round 2 was to ask respondents a series of contingent behavior questions regarding their oyster consumption having been subject to the counter-information/source treatment.

As a reference point for these future contingent behavior questions, respondents were asked an initial revealed preference question regarding their average number of oyster meals eaten in a typical month. ${ }^{6}$ Respondents were then guided through the survey instrument where they were presented with each information treatment followed by a contingent behavior question regarding how their expected monthly meals consumed would change. It should be noted that individuals that responded to both surveys were asked to report their baseline consumption levels twice. Changes from baseline levels due to price changes in round 1 of the survey were used to measure the slope of the oyster demand function. Changes from baseline levels in round 2 were used to measure the shifts in demand due to the news and counter-information treatments. This can impact 
consumer surplus estimates as respondents could change their stated baseline levels between rounds. For example, respondents that report different baseline levels in round 1 alter the slope of their demand function, which will filter through to our absolute welfare measures. However, the focus of the research is on the relative magnitude of the shifts in demand after the different information treatments. As all shifts are measured with respect to the same base in expected meals, the relative magnitudes of the shifts, and therefore the relative changes in consumer surplus will not be altered.

Respondents were first asked to read a fictitious newspaper article (modeled on a sample of actual publications) regarding the death of a Texas man as a result of eating raw oysters. A contingent behavior question then asked respondents how they would change their monthly oyster consumption if the death reported in the press release were to occur. Specifically, respondents were asked:

"Thinking about oyster meals again, suppose that the average price of your oyster meals stays the same. Compared to the [number] $]^{7}$ oyster meals you previously told us you eat in a typical month, do you think you will eat more, less, or about the same number of oyster meals in the next month that you eat oysters after learning about the recent death in the article you just read?"

Respondents were then asked to quantify how many more or less meals depending on their answer.

Next, respondents were shown an image of a tri-fold color pamphlet, currently produced by the ISSC, as an educational brochure providing the pertinent facts concerning the actual risks associated with Vibrio v. and oyster consumption, as well as information on the specific human health conditions necessary to be at risk, and a 
reiteration that only consumption of raw oysters poses a risk to human health. By survey design, the source of the educational brochure was randomly varied across respondents. Before being presented with the brochure, respondents were provided with textual material stating both the source of information and its mission. Also, when subjected to the brochure, the source was again clearly identified. Source 1 was a government associated set of organizations - specifically, the Interstate Shellfish Sanitary Conference (ISSC)/Food and Drug Administration (FDA). Source 2 was a researcher-created fictitious Vibrio v. education program "brand identity" ("The American Shellfish Foundation") developed as a proxy for a not-for-profit, non-governmental organization whose mission is to promote the production of safe shellfish products and to support educational and prevention programs for shellfish-related disease and other health risks. The third source treatment level was not sourced to any agency or organization and provided a control condition. Respondents were then asked how the counterinformation/source treatment would change their monthly oyster consumption behavior.

The impact of PHP oysters was examined by exposing respondents to textual material containing non-technical educational information about the concept and efficacy of various types of PHP treatments to mitigate the risk of Vibrio v. infection. Essentially, there are four PHP systems approved by the FDA - pressurization, pasteurization, freezing, and irradiation. All PHP systems are designed to reduce Vibrio v. bacteria in oysters to non-detectable levels. Also, PHP systems kill spoilage bacteria, extending the shelf life and maintaining the freshness and quality of oysters. As a result, PHP systems have the potential to reduce consumers' perceived risk of Vibrio v.-related illnesses and to create significant welfare gains. After being provided information about the efficacy of 
PHP treatments, respondents were again asked how their anticipated oyster consumption would change.

Finally, respondents were informed that adoption of PHP procedures would likely result in a price increase for the typical oyster meal. By survey design, respondents were randomly assigned one of four price premiums ${ }^{8}$ and were asked for the final time how their oyster consumption would change relative to their initial quantity consumed.

\section{Data}

In the round 1 telephone survey phase of the study, 3,444 eligible potential respondents were contacted, with 615 (a 17.8\% base response rate) agreeing to participate and completing the telephone data collection process. ${ }^{9}$ Of that base, 368 respondents (59.8\%) identified themselves as oyster consumers and $435(70.8 \%)$ indicated that internet access was available to them. Of the 368 oyster consumers, 340 (a 92.4\% conversion rate) agreed to participate in the round 2, web-based portion of the study. Of those agreeing to participate in round 2, 103 (a 30.3\% conditional response rate) actually logged into the study website after initial notification and one reminder and completed the experimental procedure. There were 24 incomplete responses leaving 79 usable observations ( $23.2 \%$ response rate) for the panel model. The modest sample of oyster consumers for the model is a function, primarily of the difficulty in contacting respondents willing to participate in the survey process, and in particular, oyster consumers.

Tables 1 and 2 provide definitions and descriptive statistics for the variables collected in the survey and used in the analysis. Several meal count characteristics 
immediately stand out. First, respondents consume, on average, 2.24 oyster meals in a typical month. The average number of oyster meals respondents expect to consume then decreases to 2.14 following news of an oyster-related human mortality. Average expected meals then vary depending on the counter-information/source and PHP treatments. Finally, $94 \%$ of the sample was Caucasian, $42 \%$ were male, average household income was $\$ 76,000$, and there were 2.5 people per home.

Insert Table 1 and 2 here

\section{Estimation Methodology}

In estimation, an oyster-related human mortality is treated as a factor influencing an individual's perceived risk of oyster consumption, which, in turn, has an influence on an individual's demand for oysters. Over a fixed time period, an oyster consumer's indirect utility function can be expressed as

$$
v=v(p, q, y, s, r(h))
$$

where $p$ is the price of an oyster meal, $q$ is the price of a composite of all other goods, $y$ is an individual's income over the relevant time period, $s$ is a vector of socio-demographic variables believed to influence the demand for oysters, and $r$ is the perceived quality of oysters as a function of a vector of attributes that influence this perception, where $h_{i}$ is one of $i$ elements in the vector $r$. Elements in $h$ pertain to the hypothetical information treatments associated with an oyster-related human mortality used in the contingent behavior application of the survey design. Specifically,

$$
h=n e w s, b r o c_{-} c o n t, b r o c_{-} i s s c, b r o c_{-} n f p, p h p, p h p_{-} \text {prem }
$$


where news is a binary variable representing a fictitious newspaper article regarding a human death related to consuming raw oysters, broc_cont, broc_issc, and broc_nfp are binary variables representing a color tri-fold brochure regarding the safety of oyster consumption with no provided source (control group), sourced to the ISSC/FDA, and sourced to a not-for-profit organization, respectively. Finally, php_prem is the price premium placed on a generic post-harvest processing treatment, $p h p$.

By Roy's identity, the uncompensated demand function for oyster meals can be expressed as

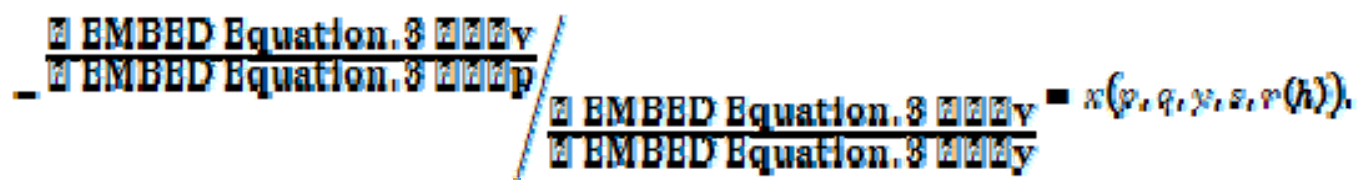

Following Parsons et al., linear forms for $r(h)$ and $x(p, q, y, s, r(h))$ were used to estimate oyster demand and the impact of an oyster-related human mortality and additional information treatments on demand.

The basic linear model can be written as

$$
x=f(p, q, y, s, S P, r(h))
$$

where an individual's number of actual/expected oyster meals consumed $(x)$, is a function of the explanatory variables. Within the stated preference literature, research has shown that values for non-market goods derived from stated preference survey techniques often exceed revealed values (List and Gallet; Murphy et al.). Therefore, we also included a stated preference elicitation dummy, $S P$, to account for and measure any hypothetical bias present in the stated preference meal counts (Egan and Herriges; Whitehead). 
As the dependent variable is a nonnegative integer with a high frequency of small numbers, a linear count data specification was investigated in an attempt to estimate the relationship between information treatments and demand for oysters. ${ }^{10}$ The Poisson model is typically used to study data of this nature. However, a critical and limiting assumption of the Poisson model is that the conditional mean of the dependent variable, $\lambda$, equals the conditional mean, that is, the variance-mean ratio is unity. This is a restricting assumption as count data often exhibit overdispersion of the population with the variance greater than the mean, giving a variance-mean ratio greater than one. As such, overdispersion is a form of heterogeneity. A less restrictive model is the negative binomial model, which is a generalized version of the Poisson model and estimates an additional overdispersion parameter. It has been shown that as the dispersion goes to zero, the negative binomial model approaches the Poisson distribution (Agresti). As the Poisson model is a special case of the negative binomial model, a standard likelihood ratio test can be used to compare the models.

Following Haab and McConnell the appropriate negative binomial model probability function with a gamma distributed error term in the mean for an individual can be expressed as

$$
\operatorname{Pr}(x)=\frac{\Gamma\left(x+\frac{1}{\alpha}\right)}{\Gamma(x+1) \Gamma\left(\frac{1}{\alpha}\right)}\left(\frac{\frac{1}{\alpha}}{\frac{1}{\alpha}+\lambda}\right)^{\frac{1}{\alpha}}\left(\frac{\lambda}{\frac{1}{\alpha}+\lambda}\right)^{x}
$$

where $\Gamma$ denotes a gamma distribution, $\alpha$ is the overdispersion parameter, and the parameter, $\lambda$, is the expected number of meals consumed and is assumed to be a function 
of the variables specified in the model. Usually, $\lambda$ takes a log-linear form to ensure nonnegative meals and may be written as

$$
\begin{aligned}
& \ln (\lambda)=\beta_{p} p+\beta_{q} q+\beta_{\text {inc }} \text { inc }+\beta_{\text {gend }} \text { gend }+\beta_{\text {race }} \text { race }+\beta_{\text {house }} \text { house }+ \\
& \beta_{\text {news }} n e w s+\beta_{\text {broc_cont }} \text { broc_cont }+\beta_{\text {broc_issc }} \text { broc_issc }+ \\
& \beta_{\text {broc_nfp }} \text { broc_nfp } n+\beta_{\text {php }} p h p+\beta_{\text {php_prem }} p h p_{-} \text {prem }+\beta_{S P} S P
\end{aligned}
$$

where the $\beta$ 's are the coefficients to be estimated.

Pooling the data suggests that a panel data model be used to account for differences in variance across individuals and consumption choice scenarios. That is, we recognize that there are likely unobserved individual specific factors that are correlated across respondents' five responses. We estimate a balanced negative binomial panel model with random effects to allow the error term in the model to be correlated across consumption choice scenarios for each individual. ${ }^{11}$

Using the estimated coefficients, a welfare measure, or consumer surplus, is calculated under each information treatment. Consumer surplus represents a measure that the individual places on monthly oyster meals consumed and is estimated as the difference between total willingness to pay for a typical oyster meal and the price of a meal. From the linear model, consumer surplus per meal is calculated as

$$
C S=\frac{1}{-\beta_{p}}
$$

where $\beta_{p}$ is the coefficient on the price of an oyster meal. Consumer surplus estimates after the information treatments were calculated using the relevant independent variable. The effect of an independent variable on the per meal consumer surplus is

$$
\Delta C S=\frac{\theta}{-\beta_{p}}
$$


where $\theta$ is the coefficient on the independent variable.

\section{Results}

Results from the negative binomial models with random effects are presented in Table 3. We estimate three versions of the model. Model 1 is the basic model as described in Equation (6). We also provide two interactive models. In Model 2, we test whether the change in demand after news of a Vibrio v.-related health scare differs for raw oyster consumers by adding an interaction term (news_raw). Model 2 is formally written as

$$
\begin{aligned}
& \ln (\lambda)=\beta_{p} p+\beta_{q} q+\beta_{\text {inc }} \text { inc }+\beta_{\text {gend }} \text { gend }+\beta_{\text {race }} \text { race }+\beta_{\text {house }} \text { house }+ \\
& \beta_{\text {news }} n e w s+\beta_{\text {broc_cont }} \text { broc_cont }+\beta_{\text {broc_issc }} \text { broc_issc }+ \\
& \beta_{\text {broc_nfp }} \text { broc_nfp }+\beta_{\text {php }} p h p+\beta_{\text {php_prem }} p h{ }_{-} \text {prem } \\
& +\beta_{S P} S P+\beta_{\text {news_raw }} \text { news_raw }
\end{aligned}
$$

where $\beta_{\text {news_rawn }}$ news_raw is the marginal effect on demand of raw oyster consumers due to news of a Vibrio v.-related health scare. Recall, by survey design, we ask respondents whether they eat raw or cooked oysters, or both, so we can isolate the behavior of consumers of the product specific to the health scare. Finally, Model 3 examines the impact of the counter-information treatment sourced to the not-for-profit organization on raw oyster consumers. The model is given by

$$
\begin{aligned}
& \ln (\lambda)=\beta_{p} p+\beta_{q} q+\beta_{\text {inc }} i n c+\beta_{\text {gend }} \text { gend }+\beta_{\text {race }} \text { race }+\beta_{\text {house }} \text { house }+ \\
& \beta_{\text {news }} n e w s+\beta_{\text {broc_cont }} \text { broc_cont }+\beta_{\text {broc_issc }} \text { broc_issc }+ \\
& \beta_{\text {broc_nfp }} \text { broc_nfp }+\beta_{\text {php }} p h p+\beta_{\text {php_prem }} p h p_{-} \text {prem }+ \\
& \beta_{S P} S P+\beta_{\text {nfp_raw }} n f p \_r a w
\end{aligned}
$$


where $\beta_{n f p_{-} r a w} n f p_{\text {r raw }}$ is the marginal effect on demand of raw oyster consumers due to the counter-information treatment sourced to the not-for-profit organization.

In each model, the positive and significant alpha value indicates that overdispersion is present in the data, suggesting that the standard errors in a Poisson model will be underestimated and the negative binomial model is the more appropriate of the two.

\section{Insert Table 3}

Table 4 contains the consumer surplus estimates from all three models associated with an oyster meal plus the change in consumer surplus associated with the counterinformation/source and PHP treatments. In calculating our consumer surplus measurements, we follow Parsons et al. and present all estimates on a per meal basis. While our consumer surplus measures provide a useful quantification of the behavioral responses due to the news and counter-information treatments, they do require some limiting assumptions. Primarily, we do not account for substitution effects. As consumers seek to maximize utility, after news of the health scare, impacted consumers likely switch to a (perceived) relatively less risky option. Failure to account for substitution means that our estimates likely provide an upper bound on the decrease in welfare due to news of the health scare. Also, the contingent behavior nature of the analysis does not account for temporal effects. Other market data research finds that changes in welfare may be shortlived in the absence of frequent message repetition (e.g., Dahlgran and Fairchild; Piggot and Marsh). As such, our welfare effects are short term and may diminish over time.

Insert Table 4 
The basic panel model (Model 1) results produced several findings worthy of note. First, the average consumer surplus estimate for an oyster meal is approximately $\$ 11$ per meal.

Next, the price coefficient is, as expected, negative and significant indicating a downward sloping oyster demand curve as consumers behave in line with conventional economic theory.

All socio-demographic variables are significant at the five percent level. The negative coefficient on inc suggests that higher income earning individuals consume less oysters, so oysters are an inferior good. This finding is supported by Hanson et al. in their 2000-2001 survey of oyster consumer opinions and preferences in which they found that the highest probability of consuming oysters occurred in the lowest income group. Other consumer characteristic variables indicate that there is a statistically significant difference in the gender and race of oyster consumers with white males more likely to consume oysters. Also, household size is important as larger households consume more oysters.

The stated preference elicitation dummy, $S P$, is positive but not significant across models, implying that stated preference elicitation does not have an effect on demand in the contingent behavior framework.

Turning to the experimental information treatments, in our basic model, a major finding of interest is that the news coefficient is negative but not significant, so news of a human mortality associated with oyster consumption has no effect on demand. This could suggest that the oyster consumers sampled exhibit optimistic bias, believing that they are less likely to experience health problems associated with their consumption of oysters than others. As such, news of a health scare does not change behavior. In this case, we 
argue that any optimistic bias may not be without cause. Some research has illustrated that optimistic bias can be associated with increased attention to risk information (Taylor and Brown; Armor and Taylor). Perhaps oyster consumers are fully informed about the minimal risks of consuming the product, and that the risks are already factored into the consumption decision. As such, new health scare information does not alter risk perceptions, and so, behavior does not change. This effect is in contrast to other food safety health scares that can act as exogenous shocks to the demand function. For example, salmonella risks from consuming tomatoes or Pfiesteria-related fish kills are likely to be generally unknown risks prior to media coverage, and as such, news of contamination can have a significant effect on behavior.

We further examine this issue by testing whether consumers of raw oysters respond differently to the news treatment than consumers of cooked oysters.

Interestingly, in Model 2, the news_raw coefficient is positive and significant, indicating that raw oyster consumers are more inclined to increase their consumption after a health scare event relative to cooked oyster consumers. This provides useful insight into the contrasting behavior of our two groups. While results suggest that consumers of cooked oysters are more risk averse (perhaps explaining why they cook their oysters), and take precautionary measures to protect against any potential risk, it is raw oyster consumers that exhibit optimistic bias behavior. The finding that raw oyster consumers are more likely to respond positively to the news release is supported by research that indicates information conveying the risks of certain health hazards can exaggerate optimistic bias, leading individuals to increase their consumption (Weinstein and Klein). In terms of the consumer surplus results, the increase in per meal welfare incurred by raw oyster 
consumers (\$3.60) almost completely offsets the decrease in per meal welfare $(\$ 4.12)$ of all our sampled consumers after the news release.

Next, the effects of counter-information, designed to reassure oyster consumers about the safety of oysters, was examined using the educational brochure treatments broc_cont, broc_issc, and broc_nfp. Previous research indicated that positive information treatments do not have a counteracting influence of reassuring consumers about a product's safety following a health scare incident (Parsons et al.; Brown and Schrader). However, earlier food safety research did not allow for variation in source in the provision of information treatments. By varying the educational brochure by source, the effectiveness of different educational treatment/source combinations in mitigating initial welfare losses was tested. Recall that respondents were informed of the source of the counter-information and its logo was clearly identified on the brochure itself. In Model 1, the insignificant coefficient on broc_cont suggests that counter-information with no identified source has no statistical impact on demand, supporting the findings of previous research that expert risk opinion has little impact on consumer behavior. This result also holds for counter-information sourced to the ISSC/FDA (broc_issc), indicating that respondents perhaps deem the message to be in the interests of the government agency, and as such, the message is discounted. However, when the counter-information is sourced to a not-for-profit organization ("The American Shellfish Foundation"), results suggest this treatment/source combination has an effect on increasing demand for oyster meals. ${ }^{12}$ The size of the broc_nfp coefficient is also important. The positive effect of the counter-information sourced to the not-for-profit organization increases per meal consumer surplus by approximately $\$ 2.87$. 
This result has important policy-based implications. As the oyster industry, the ISSC, and other agencies continue efforts to develop consumer education strategies relating to consumer awareness of oyster safety and Vibrio v., these findings suggest that source credibility is an important component in the efficacy of educational treatments. The results here indicate that consumers may perceive not-for-profit organizations as more credible sources of information, and as such, have a greater impact on consumer safety reassurance associated with oyster consumption.

Again, we test whether raw oyster consumers behave differently, this time, due to the counter-information treatment sourced to a not-for-profit organization. ${ }^{13}$ Results from Model 3 suggest that it is the consumers of raw oysters that are the most responsive, significantly increasing their demand for oysters after the information treatment from a trusted source. Again, we believe optimistic bias plays a role. Other research indicates that optimistic bias is present in individual behavior for hazards where consumers can identify with a prominent "at risk" individual (Miles and Scaife). Perhaps the treatment reaffirms that only individuals with specific health conditions are at risk from consuming raw oysters, therefore, the brochure and trusting source encourages further consumption for consumers of raw oysters.

Finally, $p h p$ is negative and insignificant suggesting that consumers do not respond favorably to a PHP-treated oyster. One potential reason is that, unlike seafood inspection programs that guarantee a product's safety, PHPs actually treat the oyster to reduce the Vibrio v. bacteria to non-detectable levels. As such, the treatment may affect the taste and texture of the product, producing, in the opinion of some consumers, an inferior product. This has important policy implications for oyster processing companies 
that invest substantial funds into PHP equipment as our findings suggest that a treated oyster has no impact on demand. Finally, to further support the argument that consumers do not favor PHP treatments, a treated oyster with an associated price premium has a significant effect on reducing demand.

\section{Conclusion}

A web-based contingent behavior analysis of oyster consumers is developed to quantify changes in consumer behavior as a result of news of an oyster-related human mortality and a counter-information and generic PHP treatment. We find that consumers of raw oysters and cooked oysters behave differently after the news release. We posit that raw oyster consumers exhibit optimistic bias, believing that they are not susceptible to the risks associated with oyster consumption. This belief may be a function of being fully informed about the actual risks of consuming raw oysters. As such, new information of an oyster-related health scare does not change their behavior. In contrast, consumers of cooked oysters are more risk averse, taking precautionary measures to protect themselves against potential risk after a press release.

Further, while previous research finds that, generally, counter-information has little impact on consumer behavior, the impact of source credibility in information provision has not been tested. By varying counter-information treatments by source, we find that a treatment sourced to a not-for-profit, non-governmental organization significantly increases demand for oyster meals following news of an oyster-related human mortality. As a result, consumers' per meal welfare increases by approximately \$2.90. Again, we find that it is raw oyster consumers that are the most responsive, 
increasing their demand for oysters following the brochure treatment, suggesting that the information reaffirms their opinion that they are not at risk from their consumption behavior.

Our findings do suggest that the oyster industry, ISSC, and other government agencies should consider the role of source credibility in future consumer education strategies to optimize the impact of informational treatments on consumer behavior. Finally, we also find that a treated oyster has no impact on demand and that further investigation within the oyster industry on the impacts of different PHP treatments is warranted.

We believe that our research and findings provide a significant contribution to the food safety literature and offer important policy-based findings for industry and state governments involved in developing consumer education treatments and outreach programs. We also hope that it provides a base for future research to examine the role of source in consumer education treatments. Based on our results, we intend to expand the sample size in experimental treatments to a larger survey of oyster producing state and include more treatment/source combinations to examine this issue further. 


\section{Footnotes}

1. For example, Swartz and Strand analyzed the impact of news associated with the prohibition of harvesting oysters in the James River, Virginia, on the demand for oysters in the Baltimore market; Smith, van Ravenswaay, and Thompson measured the impact of milk ban news on the demand for milk in Hawaii; Brown and Schrader investigated the effects of cholesterol media coverage on the demand for eggs; Wessells and Anderson analyzed the impact of news about domoic acid contamination of mussels on the demand for mussels; and Miles and Frewer examined the impacts of news of "Mad Cow" disease on the demand for beef in the UK.

2. Swartz and Strand termed the welfare losses associated with decreased consumption "avoidance costs."

3. Parsons et al. found that a mandatory seafood inspection program had a significant positive effect on seafood demand.

4. By survey design, respondents are randomly presented with a price increase of $\$ 1$, $\$ 3, \$ 5$, or $\$ 7$.

5. Each link contained an unobtrusive identifier code specific to the individual, allowing round 1 telephone and round 2 web data to be matched for each research participant.

6. Respondents were told that an oyster meal can be eaten either in their home or in restaurants and include meals where their main course was oysters, meals when oysters were an important ingredient in a dish like gumbo, or meals where they ate just an oyster appetizer.

7. As part of the web-based survey, the baseline stated number of oyster meals consumed in a typical month is automatically inserted into the text.

8. The price premiums associated with the implementation of PHP procedures are randomly assigned as either $\$ 1, \$ 3, \$ 5$, or $\$ 7$. 
9. Eligible for participation means the respondent lived in Florida and was over the age of 18. This includes both oyster consumers and non-consumers.

10. See Creel and Loomis and Hellerstein for a full discussion of count data models.

11. In estimation, there are 79 usable observations for each of the six stacked equations, giving a total of 474 observations for use in the model.

12. This result supports findings in the ecolabeling research arena (for example, Milgrom and Roberts, Johnston et al., Huffman and Tegene, and Huffman et al.) that suggests consumers are more trusting of independent, third party, information.

13. As only the counter-information treatment sourced to the not-for-profit organization is significant, we do not provide an interaction with the other two treatments. 


\section{References}

Agresti, A. Categorical Data Analysis. New York: John Wiley \& Sons, 1990.

Armor, D.A., and S.E. Taylor. "Situated Optimism: Specific Outcome Expectancies and Self-regulation." Advances in Experimental Social Psychology 30(1998):309-379.

Brown, D.J., and L.F. Schrader. "Cholesterol Information and Shell Egg Consumption." American Journal of Agricultural Economics 72(1990):548-555.

Corcoran, L. Raw Oysters: Deadly Delicacy. Nutritional Action Healthletter, 1998. Internet site: http://findarticles.com/p/articles/mi_m0813/is_n8_v25/ai_21245202/ (Accessed September 21, 2008).

Crano, W. "Effect of Sex, Response Order, and Expertise in Conformity: A Dispositional Approach." Sociometry 33(1970):239-252.

Creel, M.D., and J.B. Loomis. "Confidence Intervals for Welfare Measures with Application to a Problem of Truncated Counts." The Review of Economics and Statistics 73(1990):370-373.

Dahlgran, R.A., and D.G. Fairchild. "The Demand Impacts of Chicken Contamination Publicity - A Case Study." Agribusiness 18(2002):459-474.

Egan, K., and J. Herriges. "Multivariate Count Data Regression Models with Individual Data from an On-site Sample." Journal of Environmental Economics and Management 52(2006):567-581.

Flattery, J., and M. Bashin. A Baseline Survey of Raw Oyster Consumers in Four States. International Shellfish Sanitation Conference 2003. Internet site: http://www.issc.org/ Vibrio_vulnificus_Education/Baseline\%20Survey.pdf (Accessed April 15, 2008).

Florida Department of Agriculture and Consumer Services, Division of Aquaculture. Florida Vibrio vulnificus Risk Reduction Plan for Oysters 2005. Internet site: http://www.floridaaquaculture.com/publications/VVriskreduction.pdf (Accessed December 10, 2008).

Haab, T.C., and K.E. McConnell. Valuing Environmental and Natural Resources: The Econometrics of Non-market Valuation. Northampton, MA: Edward Elgar, 2002.

Hanson, T.L., L. House, S. Sureshwaren, B. Posadas, and A. Liu. Opinions of U.S. Consumers toward Oysters: Results of a 2000-2001 Survey. U.S. Department of Agriculture, Agreement \#99-38614-8202, Mississippi Alabama Sea Grant Consortium, 2003. Internet site: http://www.aquanic.org/species/shellfish/documents/b1133.pdf (Accessed September 17, 2007). 
Hellerstein, D. "Can We Count on Count Models." Valuing Recreation and the Environment: Revealed Preference Methods in Theory and Practice. J.A. Herriges and C.L. Kling, eds. Cheltenham, UK: Edward Elgar, 1999.

Hovland, C.I., and W. Weiss." The Influence of Source Credibility on Communication Effectiveness." Public Opinion Quarterly 15(1951):635-650.

Huffman, W.E., and A. Tegene. "Public Acceptance of and Benefits from Agricultural Biotechnology: A Key Role for Verifiable Information." Market Development for Genetically Modified Food. V. Santaniello, R.E. Evenson, and D. Zilberman, eds. New York, NY: CAB International, 2002.

Huffman, W.E., M. Rousu, J.F. Shogren, and A. Tegene. "Who Do Consumers Trust for Information: The Case of Genetically Modified Foods?" American Journal of Agricultural Economics 86(2004):1222-1229.

Johnson, H., and I. Steiner. "The Effects of Source on Response to Negative Information about One's Self.” Journal of Social Psychology 74(1968):215-224.

Johnston, R.J., C.R. Wessells, H. Donath, and F. Asche. "Measuring Consumer Preferences for Ecolabeled Seafood: An International Comparison." Journal of Agriculture and Resource Economics 26(2001):20-39.

List, J.A., and C.A. Gallet. "What Experimental Protocol Influence Disparities Between Actual and Hypothetical Stated Values?" Environmental and Resource Economics 20(2001):241-254.

Miles, S., and L.J. Frewer. "Investigating Specific Concerns about Different Food Hazards." Food Quality and Preference 12(2001):47-61.

Miles, S., and V. Scaife. “Optimistic Bias and Food.” Nutrition Research Reviews 16(2003):3-19.

Milgrom, P., and J. Roberts. "Relying on the Information of Interested Parties." RAND Journal of Economics 17(1986):18-32.

Murphy, J. J., P.G. Allen, T.H. Stevens, and D. Weatherhead. “A Meta-Analysis of 
Hypothetical Bias in Stated Preference Valuation." Environmental and Resource

Economics 30(2005):313-325.

Parsons, G.R., O.A. Morgan, J.C. Whitehead, and T.C. Haab. "The Welfare Effects of Pfiesteria-Related Fish Kills in Seafood Markets: A Contingent Behavior Analysis." Agricultural and Resource Economic Review 35(2006):1-9.

Piggot, N.E., and T.L Marsh. "Does Food Safety Information Impact U.S. Meat Demand?” American Journal of Agricultural Economics 86(2004):151-174.

Shepherd, R. "Social Determinants of Food Choice." Proceedings in the Nutrition Society 58(1999):807-812.

Shulstad, R.N., and H.H Stoevener. "The Effects of Mercury Contamination in Pheasants on the Value of Pheasant Hunting in Oregon." Land Economics 54(1978):39-49.

Smith, E., E.O. van Ravenswaay, and S.R. Thompson. "Sales Loss Determination in Food Contamination Incidents: An Application to Milk Bans in Hawaii." American Journal of Agricultural Economics 70(1988):513-520.

Sparks, P. and R. Shepherd. "Public Perceptions of the Potential Hazards Associated with Food Production and Food Consumption: An Empirical Study." Risk Analysis 14(1994):799-806.

Sternthal, B.P., W. Lynn, and R. Dholakia. "The Persuasive Effect of Source Credibility: A Situational Analysis." Public Opinion Quarterly 41(1978):285-314.

Swartz, D.G., and I.E. Strand. "Avoidance Costs Associated with Imperfect Information: The Case of Kepone." Land Economics 57(1981):139-150.

Taylor, S.E., and J.D. Brown. "Illusion and Well-being: A Social Psychological Perspective on Mental Health." Psychological Bulletin 103(1988):193-210.

Weinstein, N.D., and W.M. Klein. "Resistance of Personal Risk Perceptions to Debiasing Interventions." Health Psychology 14(1995):132-140.

Wessells, C.R., and J.G. Anderson. "Consumer Willingness to Pay for Seafood Safety Assurances." Journal of Consumer Affairs 29(1995):85-107.

Whitehead, J.C. "Environmental Risk and Averting Behavior: Predictive Validity of Jointly Estimated Revealed and Stated Behavior Data." Environmental and Resource Economics 32(2005):301-316. 
Table 1. Variable Definitions

\begin{tabular}{|c|c|}
\hline Q_typical & Number of oyster meals consumed in a month \\
\hline Q_price & $\begin{array}{l}\text { Number of oyster meals respondents expect to consume in a } \\
\text { month following a price increase }\end{array}$ \\
\hline Q_news & $\begin{array}{l}\text { Number of oyster meals respondents expect to consume in a } \\
\text { month following news of an oyster-related human mortality }\end{array}$ \\
\hline Q_cont & $\begin{array}{l}\text { Number of oyster meals respondents expect to consume in a } \\
\text { month having read the counter-information brochure with no } \\
\text { source (control group) }\end{array}$ \\
\hline Q_issc & $\begin{array}{l}\text { Number of oyster meals respondents expect to consume in a } \\
\text { month having read the counter-information brochure, sourced to } \\
\text { the ISSC/FDA }\end{array}$ \\
\hline Q_nfp & $\begin{array}{l}\text { Number of oyster meals respondents expect to consume in a } \\
\text { month having read the counter-information brochure, sourced to } \\
\text { "The American Shellfish Foundation" - a not-for-profit } \\
\text { organization }\end{array}$ \\
\hline Q_php & $\begin{array}{l}\text { Number of oyster meals respondents expect to consume in a } \\
\text { month assuming the oysters have been treated with a generic } \\
\text { PHP }\end{array}$ \\
\hline Q_php_prem & $\begin{array}{l}\text { Number of oyster meals respondents expect to consume in a } \\
\text { month assuming the oysters have been treated with a generic } \\
\text { PHP, plus a price premium }\end{array}$ \\
\hline Inc & Household income of respondent $(\$ 1,000 \mathrm{~s})$ \\
\hline Gend & Dummy variable - Male $=1,0$ otherwise \\
\hline Race & Dummy variable - White $=1,0$ otherwise \\
\hline House & Total number of people living in respondent's house \\
\hline
\end{tabular}


Table 2. Descriptive Statistics

\begin{tabular}{lcccc}
\hline Variable & Mean & Std. Deviation & Min & Max \\
\hline Q_typical & 2.24 & 1.78 & 1.00 & 12.00 \\
Q_price & 1.87 & 1.94 & 0.00 & 12.00 \\
Q_news & 2.14 & 1.82 & 0.00 & 12.00 \\
Q_cont & 1.95 & 1.10 & 1.00 & 5.00 \\
Q_issc & 2.37 & 2.21 & 1.00 & 12.00 \\
Q_nfp & 2.68 & 1.89 & 0.00 & 8.00 \\
Q_php & 2.10 & 1.86 & 0.00 & 12.00 \\
Q_php_prem & 1.61 & 1.87 & 0.00 & 12.00 \\
Inc & 76.49 & 38.65 & 15.00 & 150.00 \\
Gend & 0.42 & 0.50 & 0.00 & 1.00 \\
Race & 0.94 & 0.24 & 0.00 & 6.00 \\
House & 2.47 & 0.99 & 1.00 & \\
\hline
\end{tabular}


Table 3. Negative Binomial Model with Random Effects

\begin{tabular}{lcccccc}
\hline Variable & \multicolumn{2}{c}{ Model 1 } & \multicolumn{2}{c}{ Model 2 } & \multicolumn{2}{c}{ Model 3 } \\
& Coefficient & Std. Error & Coefficient & Std. Error & Coefficient & Std. Error \\
\hline Price & $-0.094^{* *}$ & 0.036 & $-0.094^{* *}$ & 0.036 & $-0.093^{* *}$ & 0.036 \\
Inc & $-0.001^{* *}$ & 0.000 & $-0.001^{* *}$ & 0.000 & $-0.001^{* *}$ & 0.000 \\
Gend & $0.219^{* *}$ & 0.083 & $0.190^{* *}$ & 0.082 & $0.201^{* *}$ & 0.082 \\
Race & $0.170^{* *}$ & 0.047 & $0.194^{* *}$ & 0.043 & $0.181^{* *}$ & 0.044 \\
House & $0.220^{* *}$ & 0.023 & $0.219^{* *}$ & 0.022 & $0.221^{* *}$ & 0.022 \\
News & -0.183 & 0.165 & $-0.387^{* *}$ & 0.190 & -0.181 & 0.162 \\
Broc_cont & -0.057 & 0.263 & -0.064 & 0.246 & -0.051 & 0.259 \\
Broc_issc & 0.048 & 0.158 & 0.039 & 0.159 & 0.052 & 0.153 \\
Broc_nfp & $0.272^{*}$ & 0.161 & $0.294^{*}$ & 0.167 & 0.059 & 0.189 \\
PHP & -0.328 & 0.363 & -0.327 & 0.354 & -0.358 & 0.361 \\
PHP_prem & $-0.047^{* *}$ & 0.020 & $-0.026^{* *}$ & 0.020 & $-0.049^{* *}$ & 0.021 \\
News_raw & & & $0.338^{* *}$ & 0.113 & & \\
Nfp_raw & & & & & $0.389 * *$ & 0.134 \\
SP & 0.039 & 0.158 & 0.026 & 0.154 & 0.030 & 0.155 \\
Alpha & $0.078^{* *}$ & 0.038 & $0.066^{*}$ & 0.038 & $0.069^{*}$ & 0.038 \\
\hline Log Lik. & -798.99 & & -792.02 & & -793.58 & \\
R & 0.09 & & 0.09 & & 0.09 & \\
Obs. & 474 & & 474 & & 474 & \\
\hline
\end{tabular}

* Significant at $10 \%$ level. ** Significant at $5 \%$ level. 
Table 4. Consumer Surplus per Meal Estimates

\begin{tabular}{llcc}
\hline & Model 1 & Model 2 & Model 3 \\
\hline CS per Meal & $\$ 10.64$ & $\$ 10.64$ & $\$ 10.75$ \\
$\Delta \mathrm{CS}-$ News & $-\$ 1.95$ & $-\$ 4.12$ & $-\$ 1.95$ \\
$\Delta \mathrm{CS}-$ Broc_cont & $-\$ 0.61$ & $-\$ 0.68$ & $-\$ 0.54$ \\
$\Delta \mathrm{CS}-$ Broc_issc & $\$ 0.51$ & $\$ 0.41$ & $\$ 0.55$ \\
$\Delta \mathrm{CS}-$ Broc_nfp & $\$ 2.87$ & $\$ 3.13$ & $\$ 0.63$ \\
$\Delta \mathrm{CS}-$ PHP & $-\$ 3.49$ & $-\$ 3.48$ & $-\$ 3.81$ \\
$\Delta \mathrm{CS}-$ PHP_prem & $-\$ 0.50$ & $-\$ 0.28$ & $-\$ 0.52$ \\
$\Delta \mathrm{CS}-$ News_raw & & $\$ 3.60$ & \\
$\Delta \mathrm{CS}-$ Nfp_raw & & & $\$ 4.14$ \\
\hline
\end{tabular}

